\title{
THE RELATIONSHIP BETWEEN PROPERTIES OF FLUORINATED GRAPHITE INTERCALATES AND MATRIX COMPOSITION Intercalates with acetonitrile
}

\author{
D. V. Pinakov and V. A. Logvinenko* \\ Nikolaev Institute of Inorganic Chemistry, Siberian Branch of Russian Academy of Sciences, Ac. Lavrentyev Ave. 3 , \\ 630090 Novosibirsk-90, Russia
}

Inclusion compounds: intercalates of fluorinated graphite matrix with acetonitrile $\left(\mathrm{C}_{2} \mathrm{~F}_{\mathrm{x}} \mathrm{Br}_{\mathrm{z}} \cdot y \mathrm{CH}_{3} \mathrm{CN}, x=0.92,0.87,0.69\right.$ and 0.49 , $z \approx 0.01$ ) were synthesized. The kinetics of the thermal decomposition (the $1^{\text {st }}$ stage of filling $\rightarrow$ the $2^{\text {nd }}$ stage of filling) was studied under isothermal conditions. The relationship between intercalates properties and composition and structure of the matrix is discussed.

Keywords: fluorinated carbon, fluorinated graphite, inclusion compounds, intercalates, isothermal kinetics

\section{Introduction}

Layered compounds (intercalates) based on graphite fluoride matrices with various guest molecules are supposed to be a particular group of inclusion compounds. Keen interest to these new materials is determined by their applications as so-called 'molecular containers' both for different gases (such as $\mathrm{CH}_{4}$, $\mathrm{NO}_{2}$, HF etc.) and condensed phases $\left(\mathrm{BrF}_{3}, n-\mathrm{C}_{\mathrm{n}} \mathrm{H}_{2 \mathrm{n}+2}\right.$, $\mathrm{C}_{2} \mathrm{H}_{5} \mathrm{OH}, \mathrm{C}_{6} \mathrm{H}_{6},\left(\mathrm{CH}_{3}\right)_{2} \mathrm{CO}, \mathrm{SOCl}_{2}$, etc.) [1]. Investigation of their properties is actual for predictable synthesis of new materials including functional nanosized composites.

The fluorinated graphite matrix is the host; the molecules of different substances can be defined as guests. The layered fluoro-carbon matrix contains fluorine atoms, $\mathrm{C}-\mathrm{F}$ bonds being perpendicular to graphite layers. Carbon layers are not planar because of breaking of some dual $\mathrm{C}=\mathrm{C}$ bonds in graphite and their transformations into ordinary $\mathrm{C}-\mathrm{C}$ bonds during fluorination process. The entering guest molecules are fixed as monomolecular layer in interlayer space of the fluoro-carbon cage, and this is followed by the increase of the distance between graphite layers of the matrix; this increase depends on the guest molecule size.

There are only Van der Waals interaction between the fluorinated graphite and the intercalated guest molecules, while graphite inclusion compounds have mostly donor-acceptor type of interactions $[2,3]$. That was shown by IR-spectra, where wave numbers are considerably shifted from those in pure graphite and guest components, while wave numbers of guests intercalated into fluorinated graphite are nearly similar to pure guest spectra. So as the phases

* Author for correspondence: val@che.nsk.su are layered substances, there are series of different structures: the first stage of filling (alternating unit layer of the matrix and unit layer of the guest molecules, Fig. 1a), the second stage of filling (alternating double matrix layer and one guest molecule layer, Fig. 1b), the third stage of filling etc. The first stage of filling results usually during the synthetic process, the second stage of filling is the resulting phase after 'drying' in the air at room temperature.

Intercalate formation and decomposition processes for fluorinated graphite are different from those for pure graphite inclusion compounds. Structure of $\left(\mathrm{C}_{2} \mathrm{~F}\right)_{\mathrm{n}}$ and host-guest bond character in its inclusion compounds is under research at this moment. Now several models of $\left(\mathrm{C}_{2} \mathrm{~F}\right)_{\mathrm{n}}$ structure are discussed [4-6], because of practical impossibility to synthesize monocrystals which could be suitable for direct X-ray structure analysis. The review [7] says that the model of graphite-like $\mathrm{C}_{\mathrm{sp}^{2}}$-regions and perfluorocyclohexane $\mathrm{sp}^{3}$-cells has the best conformance with physical methods data and MNDO-calculation Physicochemical in-

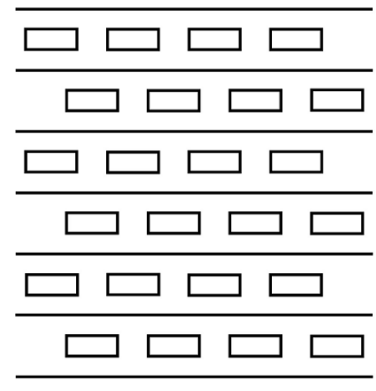

a

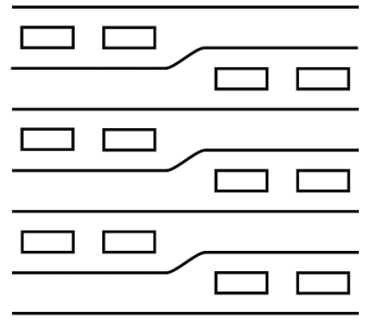

b
Fig. 1 Simplified structures of $a-$ the $1^{\text {st }}$ stage and $b-$ the $2^{\text {nd }}$ stage graphite fluoride inclusion compounds 
vestigations of $\left(\mathrm{C}_{2} \mathrm{~F}\right)_{\mathrm{n}}$ inclusion compounds is complicated because 'empty' $\alpha$-modification of fluorinated graphite does not exist: fluorinated matrix layers are generated in situ during graphite fluorination process which partially transforms initial $\mathrm{C}_{\mathrm{sp}^{2}}$-atoms into $\mathrm{sp}^{3}$-hybridization of graphite monofluoride, which has structure of regular pseudoplanar corrugated carbon frame $[8,9]$. Both thermodynamic stability and kinetic lability for intercalates with the fluorinated graphite are studied insufficiently. Thermoanalytical investigations of graphite fluoride intercalates are not numerous. In recent times inclusion compounds researched by this method are mostly based on theophylline [10], cyclodextrin $[11,12]$ and clays [13-16].

Intercalates with acetonitrile $\left(\mathrm{CH}_{3} \mathrm{CN}\right)$ are convenient for this research, because acetonitrile does not react with fluorinated matrix before its thermal decomposition and can have donor-acceptor property under specified conditions. That is the reason why we used them as model compounds. The $\mathrm{CH}_{3} \mathrm{CN}$ is shaped as symmetrical top molecule of $5.9 \AA$ height and $4.1 \AA$ width. It has boiling point $355.25 \mathrm{~K}$ and vapour pressure $10 \mathrm{kPa}$ at $293.15 \mathrm{~K}$, which allowed performing thermal research of inclusion compounds because their decomposition point is much lower than temperature of host matrix destruction. It is known that acetonitrile is typical basic compound, which is often used as a probe molecule for the study of acidic properties of solids, but we did not take this aspect into consideration.

As host matrices we chose layered $\mathrm{C}_{2} \mathrm{~F}_{\mathrm{x}}$ with different fluorine content. These inclusion compounds attract attention because they have not been researched thoroughly. Most articles are dedicated to the research of tetragraphite monofluoride $\left(\mathrm{C}_{4} \mathrm{~F}\right)_{\mathrm{n}}$ and digraphite monofluoride $\left(\mathrm{C}_{2} \mathrm{~F}\right)_{\mathrm{n}}$ properties, basically of inclusion compounds with the $2^{\text {nd }}$ stage of filling. Inclusion compounds of fluorinated graphite with the $1^{\text {st }}$ stage of filling were investigated mainly by X-ray structure analysis - determination of interplanar distances.

\section{Experimental}

Synthesis of fluorinated graphite - acetonitrile inclusion compounds was carried out by these procedures:
- Graphite oxidation in $\mathrm{BrF}_{3}-\mathrm{Br}_{2}$ solutions leading to formation of the $1^{\text {st }}$ stage inclusion compound with oxidizing medium components:

$$
\begin{aligned}
\mathrm{BrF}_{3}+\mathrm{Br}_{2} & \leftrightarrows 3 \mathrm{BrF}[17] \\
2 \mathrm{C}+1 / 3\left(2 \mathrm{BrF}_{3}+\mathrm{Br}_{2}\right) & \rightarrow \mathrm{C}_{2} \mathrm{~F} \cdot 1 / 3 \mathrm{BrF}_{3}+1 / 2 \mathrm{Br}_{2}
\end{aligned}
$$

- Isolation of the $2^{\text {nd }}$ stage inclusion compound using step-by-step guest system substitution to $\mathrm{Br}_{2}$, then to $\mathrm{CH}_{3} \mathrm{CN}$ and following desiccation [18]:

$$
\begin{aligned}
& \mathrm{C}_{2} \mathrm{~F} \cdot 1 / 3 \mathrm{BrF}_{3} \stackrel{\mathrm{Br}_{2} \text { excess }}{\longrightarrow} \mathrm{C}_{2} \mathrm{~F} \cdot a \mathrm{Br}_{2} \stackrel{\mathrm{CH}_{3} \mathrm{CN} \text { excess }}{\longrightarrow} \\
& \mathrm{C}_{2} \mathrm{~F} \cdot 2 y \mathrm{CH}_{3} \mathrm{CN} \stackrel{\text { dry }}{\longrightarrow} \mathrm{C}_{2} \mathrm{~F} \cdot y \mathrm{CH}_{3} \mathrm{CN}
\end{aligned}
$$

The inclusion compounds $\mathrm{C}_{2} \mathrm{~F}_{\mathrm{x}} \mathrm{Br}_{\mathrm{z}} \cdot y_{2} \mathrm{CH}_{3} \mathrm{CN}$ formulae, according to elemental analysis, are listed in Table 1.

The $2^{\text {nd }}$ stage inclusion compound was prepared in the following way. Graphite refined from natural admixtures (ash level $\leq 0.3 \%$, grain size $0.4 \times 0.3 \times 0.02 \mathrm{~mm}$ ) was transformed to the $1^{\text {st }}$ stage inclusion compound with bromine by placing to its atmosphere for about $24 \mathrm{~h}$. This 'unsealed' graphite was placed above $\mathrm{Br}_{2}$ and $\mathrm{BrF}_{3}$ mixture $\left(\mathrm{BrF}_{3}\right.$ concentration about $\left.11-13 \%\right)$ for soft oxidation of graphite. After 14-55 days (depends on required fluorination rate) $\mathrm{BrF}_{3}$ was removed from reaction chamber, and reaction product was washed out by acetonitrile until visual removal of bromine (colourless liquid phase).

The $1^{\text {st }}$ stage inclusion compound synthesis with acetonitrile was prepared by isopiestic method. Initial samples of the $2^{\text {nd }}$ stage compounds $(500-600 \mathrm{mg}$ ), were placed into open cylindrical cells. During this synthesis we got satiety curves - point-by-point dependences of sample mass increase from reaction time. The reaction end was determined by reaching the plateau - stopping of mass increase during $\sim 1 \mathrm{~h}$.

The thermal decomposition of the $1^{\text {st }}$ stage inclusion compounds was investigated by means of the home-made differential thermal analysis equipment. Samples (30-40 mg) were placed to ampoules with bottleneck and the hollow for thermocouple in the bottom. After deep cooling (in liquid nitrogen) we made capillaries ( $\sim 0.2 \mathrm{~mm}$ diameter and $30-35 \mathrm{~mm}$ length), which were opened after equilibrium reaching $(20-40 \mathrm{~h})$ directly before heating curve recording. In this experimental method the gas phase of guest com-

Table 1 Elemental composition and stoichiometry of $\mathrm{C}_{2} \mathrm{~F}_{\mathrm{x}} \mathrm{Br}_{\mathrm{z}} \cdot y_{2} \mathrm{CH}_{3} \mathrm{CN}$ (the $2^{\text {nd }}$ stage inclusion compounds)

\begin{tabular}{llccccccc}
\hline \multirow{2}{*}{ No. } & Colour & \multicolumn{4}{c}{ Found elements/mass\% } & & The $2^{\text {nd }}$ stage inclusion compound formula \\
$x( \pm 0.01), z( \pm 0.003), y_{2}( \pm 0.011)$ & $I_{\mathrm{c}} / \AA^{1}$ \\
\cline { 3 - 5 } & & $\mathrm{C} \pm 0.005$ & $\mathrm{~F} \pm 0.3$ & $\mathrm{~N} \pm 0.3$ & $\mathrm{Br} \pm 0.3$ & & $\mathrm{C}_{2} \mathrm{~F}_{0.92} \mathrm{Br}_{0.010} \cdot 0.136 \mathrm{CH}_{3} \mathrm{CN}$ & 15.5 \\
\hline 1 & yellow & 50.02 & 36.24 & 3.98 & 1.65 & & $\mathrm{C}_{2} \mathrm{~F}_{0.87} \mathrm{Br}_{0.010} \cdot 0.136 \mathrm{CH}_{3} \mathrm{CN}$ & 15.3 \\
2 & light green & 51.18 & 35.02 & 4.06 & 1.80 & & $\mathrm{C}_{2} \mathrm{~F}_{0.69} \mathrm{Br}_{0.009} \cdot 0.112 \mathrm{CH}_{3} \mathrm{CN}$ & 15.0 \\
3 & dark green & 56.81 & 30.92 & 3.69 & 1.76 & & $\mathrm{C}_{2} \mathrm{~F}_{0.49} \mathrm{Br}_{0.008} \cdot 0.084 \mathrm{CH}_{3} \mathrm{CN}$ & 14.4 \\
4 & black & 63.19 & 24.51 & 3.10 & 1.65 & &
\end{tabular}

${ }^{1} I_{\mathrm{c}} / \AA$ - identity period along $c$-axis 
ponent had vapour pressure about $10 \mathrm{kPa}$ [19], because inclusion compound is practically insoluble $(<0.01 \%)$ in acetonitrile. Accuracy of temperature measurement was about $0.4^{\circ} \mathrm{C}$; heating rate was $3.2^{\circ} \mathrm{C} \mathrm{min}^{-1}$.

Investigation of the $1^{\text {st }}$ stage inclusion compound thermal decomposition kinetic parameters were carried out by applying thermogravimetric method at different temperatures $\left( \pm 0.2^{\circ} \mathrm{C}\right)$ in ambient atmosphere taking the $1^{\text {st }}$ stage inclusion compound sample mass decrease point-by-point using thermostatically controlled analytical balance at different temperatures from 14 to $40^{\circ} \mathrm{C}$. Equilibrium shift was enough for kinetic investigations.

\section{Results and discussion}

The $1^{\text {st }}$ stage inclusion compounds (synthesized by the way shown above) was dried on air at a room temperature till constant mass and transformed into the $2^{\text {nd }}$ stage inclusion compound (according to X-ray structure analysis) - alternation of filled by guest and empty interlayer spaces. They differed by colour and electrization. Characteristics of these compounds are listed in Table 1.

Satiety curves of the initial $2^{\text {nd }}$ stage inclusion compound by acetonitrile are shown on Fig. 2. Equilibration time of satiety through gas phase increased with matrix fluorination degree from $1 \mathrm{~h}$ for $x=0.49$ to $12 \mathrm{~h}$ for $x=0.92$. The distinguished relation between the $1^{\text {st }}$ stage formation rate and amount of fluorine in matrix is shown on Fig. 2. X-ray structure investigations of the $1^{\text {st }}$ stage inclusion compounds demonstrated changing of interplanar spacings in comparison with the $2^{\text {nd }}$ stage and confirmed the $1^{\text {st }}$ stage structure with one guest layer after one host layer (Table 2).

Temperatures of the $1^{\text {st }}$ stage inclusion compound decomposition to the $2^{\text {nd }}$ stage and guest vapour (Fig. 3) are much higher than the boiling point of pure 'guest' $\left(82.1^{\circ} \mathrm{C}\right)$ and depend on $x$. The formation of the individual $1^{\text {st }}$ stage inclusion compound phases is proved by the fact of its regeneration (according to RCA data) after thermal decomposition in DTA chamber, cooling and placing above acetonitrile at a room temperature for 30-40 h. DTA heating curves were reproduced many times as well. The decomposition time

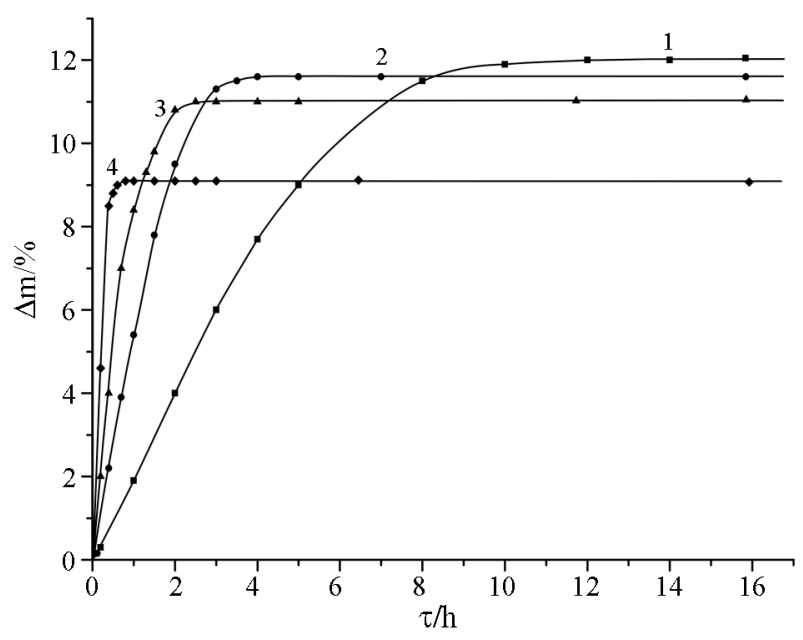

Fig. 2 Curves of the $2^{\text {nd }}$ stage inclusion compounds satiety by acetonitrile $\left(P_{\mathrm{CH}_{3} \mathrm{CN}} \approx 10 \mathrm{kPa}, T=298.15 \mathrm{~K}\right)$ for $x=0.92(1)$, $0.87(2), 0.69(3)$ and $0.49(4)$

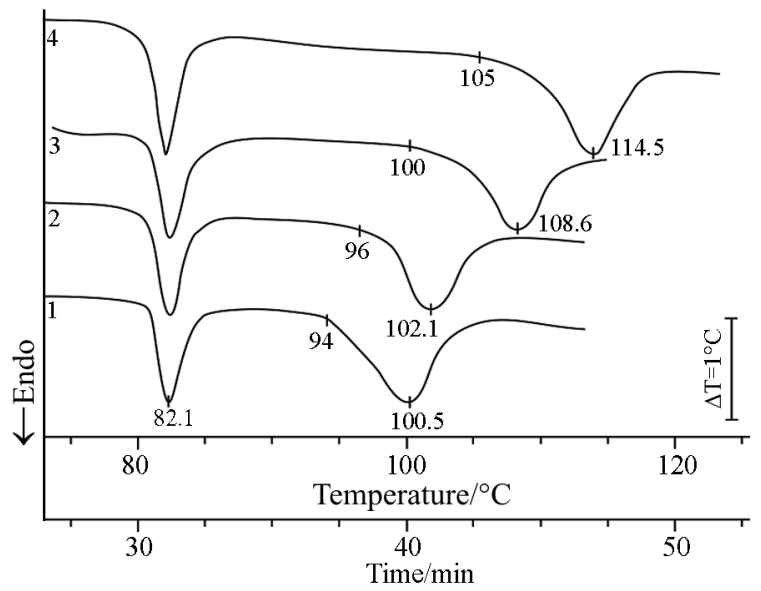

Fig. 3 Heating curves (DTA) for the $1^{\text {st }}$ stage inclusion compounds $\mathrm{C}_{2} \mathrm{~F}_{\mathrm{x}} \mathrm{Br}_{\mathrm{z}} \cdot y_{1} \mathrm{CH}_{3} \mathrm{CN}$ with $x=0.92$ (1), 0.87 (2), 0.69 (3) and 0.49 (4)

of the $1^{\text {st }}$ stage compound samples $(60-500 \mathrm{~min})$ depended both on fluorination degrees $x$, and on temperature (Figs $4 a-d)$.

Experimental data of decomposition degree $\alpha$ from time $\tau$ for each matrix at different temperatures were mapped by equation $\ln [-\ln (1-\alpha)]=n \ln (k / n)+n \ln \tau$ (getting after the two-fold taking logarithm from

Table 2 Properties of the $1^{\text {st }}$ stage inclusion compounds $\left(\mathrm{C}_{2} \mathrm{~F}_{x} \mathrm{Br}_{z} \cdot y_{1} \mathrm{CH}_{3} \mathrm{CN}\right)$ with acetonitrile

\begin{tabular}{|c|c|c|c|c|c|c|}
\hline \multirow{2}{*}{ No. } & \multirow{2}{*}{ Colour } & \multicolumn{2}{|c|}{ The $1^{\text {st }}$ stage inclusion compound stoichiometry } & \multirow{2}{*}{$\begin{array}{c}I_{\mathrm{d}} / \AA \\
( \pm 0.03)\end{array}$} & \multirow{2}{*}{$\begin{array}{c}\text { Decomposition } \\
\text { maximum } \\
(\mathrm{DTA}) /{ }^{\circ} \mathrm{C}( \pm 0.4)\end{array}$} & \multirow{2}{*}{$\begin{array}{l}\text { Activation energy/ } / \\
\mathrm{kJ} \mathrm{mol}^{-1} \text { of the } \\
1^{\mathrm{st}} \text { stage compound }\end{array}$} \\
\hline & & $\Delta m^{1} / \%( \pm 0.2)$ & Formula $y_{1}( \pm 0.017)$ & & & \\
\hline 1 & yellow & 12.0 & $\mathrm{C}_{2} \mathrm{~F}_{0.92} \mathrm{Br}_{0.01} \cdot 0.288 \mathrm{CH}_{3} \mathrm{CN}$ & 9.47 & $100.5(94)^{2}$ & $51.0 \pm 4.4$ \\
\hline 2 & light green & 11.6 & $\mathrm{C}_{2} \mathrm{~F}_{0.87} \mathrm{Br}_{0.01} \cdot 0.283 \mathrm{CH}_{3} \mathrm{CN}$ & 9.41 & $102.1(96)$ & 51.2 \\
\hline 3 & dark green & 11.0 & $\mathrm{C}_{2} \mathrm{~F}_{0.69} \mathrm{Br}_{0.01} \cdot 0.240 \mathrm{CH}_{3} \mathrm{CN}$ & 9.22 & $108.6(100)$ & 52.6 \\
\hline 4 & black & 9.1 & $\mathrm{C}_{2} \mathrm{~F}_{0.49} \mathrm{Br}_{0.01} \cdot 0.174 \mathrm{CH}_{3} \mathrm{CN}$ & 9.02 & $114.5(105)$ & $53.3 \pm 1.8$ \\
\hline
\end{tabular}

${ }^{1} \Delta m$ - sample mass increase during the $2^{\text {nd }}$ to $1^{\text {st }}$ stage inclusion compound transformation

${ }^{2}$ Initial temperatures of endothermic effects are given in parenthesis 
PINAKOV, LOGVINENKO
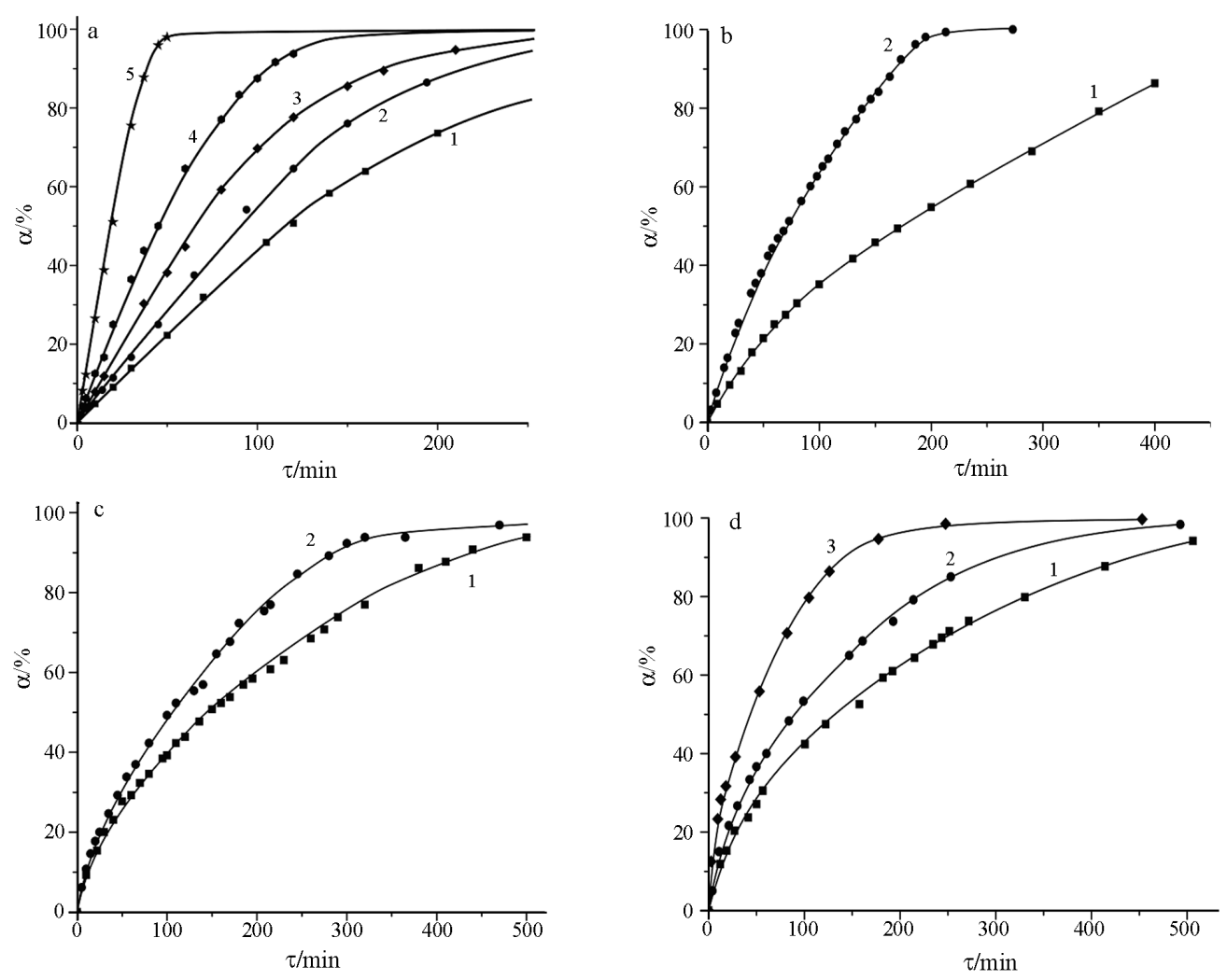

Fig. 4 Decomposition curves of the $1^{\text {st }}$ stage inclusion compounds $\mathrm{C}_{2} \mathrm{~F}_{\mathrm{x}} \mathrm{Br}_{\mathrm{z}} \cdot y_{1} \mathrm{CH}_{3} \mathrm{CN}$ : a $-x=0.92$ at $288.05 \mathrm{~K}$ (1), $291.15 \mathrm{~K}$ (2), $298.65 \mathrm{~K}(3), 300.15 \mathrm{~K}(4), 313.15 \mathrm{~K}(5) ; \mathrm{b}-x=0.87$ at $288.15 \mathrm{~K}(1), 298.65 \mathrm{~K}(2) ; \mathrm{c}-x=0.69$ at $288.55 \mathrm{~K}$ (1), $293.15 \mathrm{~K}(2) ; \mathrm{d}-x=0.49$ at $288.15 \mathrm{~K}(1), 293.15 \mathrm{~K}(2), 305.15 \mathrm{~K}$ (3)
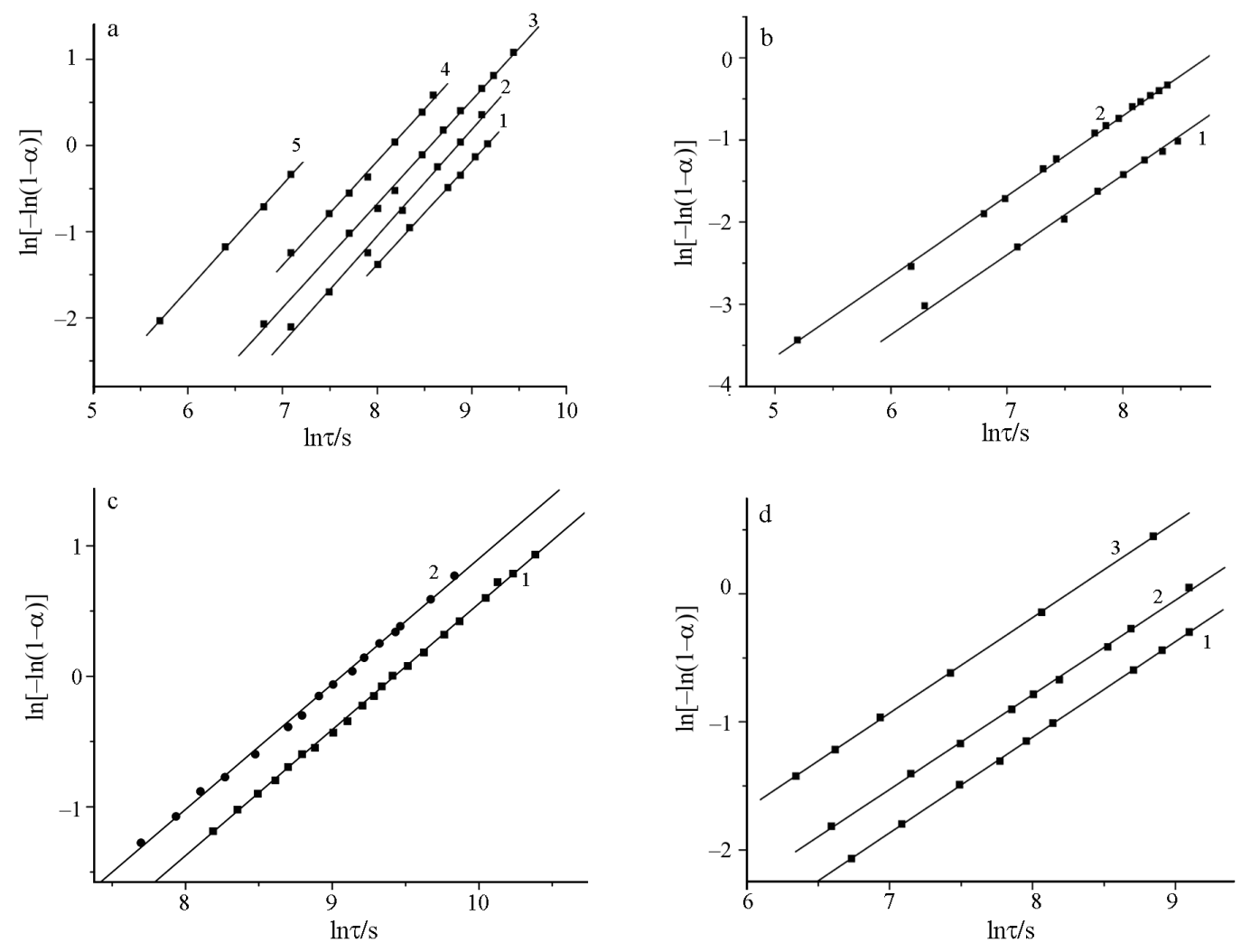

Fig. 5 Dependences of $\ln [-\ln (1-\alpha)] v s . \ln \tau$ (caption of Fig. 4) 
Erofeev's equation subject to Sakovich's correlation), where $n$-nondimensional coefficient, $k$-generalized rate constant, $\mathrm{s}^{-1}$. Equation shown above was successfully used by many authors for kinetic investigations of both thermal decomposition of different compounds (including carbamide- $n$-alkanes clathrates) and phase transitions, solvation and absorption [20]. Kinetic curves (Fig. 4) can be approximated by nearly parallel lines (Fig. 5), it points on the kinetic parameter $n$ constancy in considered range of temperatures. Coefficient $n$ had values of $1.20-1.21,0.97-0.98,0.96-0.97$, $0.74-0.75$ for $x=0.92,0.87,0.69$ and 0.49 respectively. Values $n<1$ considered to describe reaction with diffusion control, $n>1$ - with kinetic control $[19,20]$. For determination of the $1^{\text {st }}$ stage inclusion compound decomposition reaction mechanism in isothermal conditions we checked dependencies of $\mathrm{d} \alpha / \mathrm{d} \tau \nu s$. reduced time $\tau / \tau_{0.5}$ (Fig. 7) [19]. It appears that for $x=0.92$ there were three parts: nucleation in the beginning, then on phase boundary and diffusion in the end. For $x=0.49$ in the beginning there is the reaction on phase boundary, but for the most part of reaction it goes by diffusion mechanism. For intermediate matrices nucleation section of these graphs reduces with decrease of $x$ and then disappears. Activation energy $\left(E_{\mathrm{a}}\right)$ values found from line slope of $\ln k-10000 / T$ function (Fig. 6) are equal to $51.0,51.2,52.6$ and $53.3 \mathrm{~kJ} \mathrm{~mol}^{-1}$ of the $1^{\text {st }}$ stage compound for $x=0.92,0.87,0.69$ and 0.49 , respectively. It has higher value than decomposition enthalpy of these compounds to the $2^{\text {nd }}$ stage and gaseous acetonitrile, and more than pure acetonitrile evaporation heat [21]. This $E_{\mathrm{a}}$ value is much more than $E_{\mathrm{a}}$ of hexagonal urea- $n$-hexane inclusion compound decomposition $\left(14.88 \mathrm{~kJ} \mathrm{~mol}^{-1}\right.$ of inclusion compound $\left.\mathrm{CO}\left(\mathrm{NH}_{2}\right)_{2} \cdot 0.186 \mathrm{C}_{6} \mathrm{H}_{14}\right)[20]$ and comparable with $E_{a}$ of hydroquinone-acetonitrile clathrate decomposition (48.9 kJ mol ${ }^{-1}$ of inclusion compound $\mathrm{C}_{6} \mathrm{H}_{4}(\mathrm{OH})_{2}$ $\cdot 0.333 \mathrm{CH}_{3} \mathrm{CN}$ ) [19], which is sufficiently stable inclusion compound with cellular host matrix.

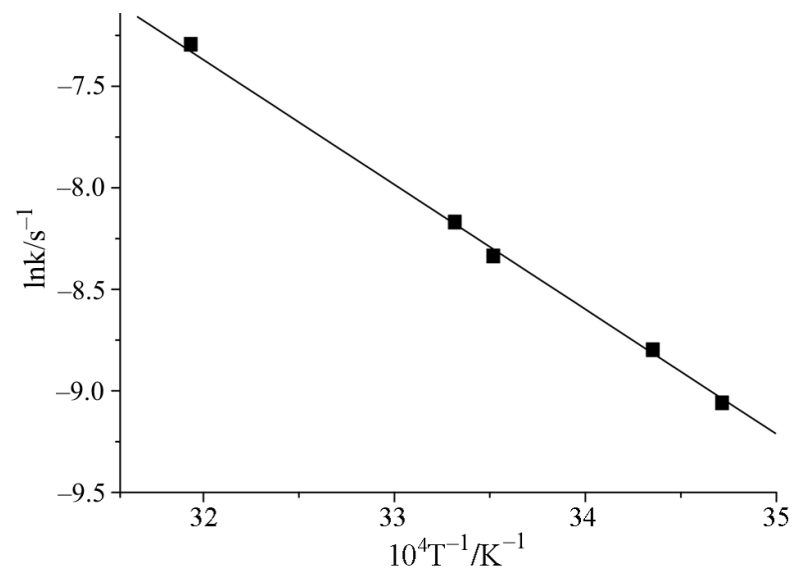

Fig. 6 Dependences of $\ln k v s .10^{4} / \mathrm{T}$ for $x=0.92$
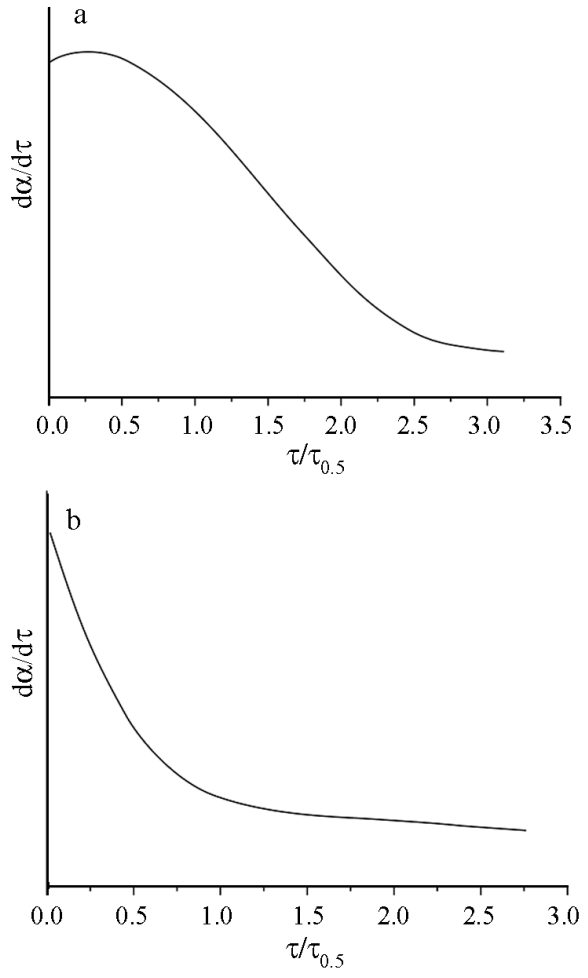

Fig. 7 Dependences of $d \alpha / \mathrm{d} \tau$ vs. reduced time $\tau / \tau_{0.5}$ for $\mathrm{a}-x=0.92$ at $T=298.65 \mathrm{~K}$ and $\mathrm{b}-$ for $x=0.49$ at $T=293.15 \mathrm{~K}$

\section{Conclusions}

Kinetic stability of the $\mathrm{C}_{2} \mathrm{~F}_{\mathrm{X}} \mathrm{Br}_{\mathrm{z}} \cdot y_{1} \mathrm{CH}_{3} \mathrm{CN} 1^{\text {st }}$ stage inclusion compounds with different fluorination degree is similar for all samples, but thermodynamic stability (according to DTA with high guest vapour pressure $\approx 100 \mathrm{kPa}$ ) considerably increases for $\mathrm{C}_{2} \mathrm{~F}_{\mathrm{x}} \mathrm{Br}_{\mathrm{z}}$ $y_{1} \mathrm{CH}_{3} \mathrm{CN}$ with decrease of $x$ and $y$. Decomposition of the $1^{\text {st }}$ stage inclusion compound to the $2^{\text {nd }}$ stage with guest removal proceeds by complex mechanism: nucleation, phase boundary reaction and diffusion. It is worth to note that the decomposition topochemical mechanism is complex: it gradually changes from phase boundary reaction (the most on $x=0.92$ ) to diffusion $(x=0.49)$, so it depends on fluorination degree. The decreasing of fluorine atoms numbers increases the diffusion hindrance for guest molecules removal through interlayer space, so as the interplanar spacing decreases at that from 9.47 till $9.02 \AA$ (Table 2). Nevertheless, this phase (with $x=0.49$ ) is formed with the highest rate (Fig. 2).

\section{Acknowledgements}

Russian Foundation for Basic Research has financially supported this study (RFBR, Grant 05-03-33209-a). 


\section{References}

1 V. A. Logvinenko and V. M. Paasonen, Chemistry for Sustainable Development, 8 (2000) 167 (in Russian).

2 M. S. Dresselhaus and G. Dresselhaus, Intercalation Compounds of Graphite, Adv. Phys., 31. (1981) 139.

3 T. Nakajima, K. Okahara, D. K. Padma and N. Watanabe, Carbon, 26 (1988) 825.

4 T. Nakajima and N. Watanabe, Graphite Fluorides and Carbon-Fluorine Compounds, FL, Boca Raton, CRC Press, (1991) p. 326.

5 Fluorine-Carbon and Fluoride-Carbon Materials: Chemistry, Physics and Applications, Ed. T. Nakajima, New York-Basel-Hong Kong: Marwel Dekker Inc., (1995) p. 403.

6 Advanced Inorganic Fluorides: Synthesis, Characterization and Applications, Eds T. Nakajima, B. Žemva and A. Tressaud, Elsevier, Amsterdam-Lausanne-New YorkShannon-Singapore-Tokyo 2000, p. 702.

7 V. N. Mit'kin, J. Struct. Chem., 44 (2003) 99.

8 R. J. Lagow, R. B. Badachape, I. L. Wood, J. Chem. Soc. Dalton. Trans., (1974), 1268.

9 N. Watanabe, T. Nakajima and H. Touhara, Graphite Fluorides. Amsterdam-Oxford-New York: Elsevier, Science Publishers B. V., (1988), p. 263.

10 J. Madarácz, P. Bombicz, K. Jármi, M. Bán, G. Pokol and S. Gál, J. Therm. Anal. Cal., 69 (2002) 281.

11 L. P. Fernandes, Zs. Éhen, T. F. Moura, Cs. Novák and J. Sztatisz, J. Therm. Anal. Cal., 78 (2004) 557.

12 Zs. Éhen, F. Giordano, J. Sztatisz, L. Jicsinszky and Cs. Novák, J. Therm. Anal. Cal., 80 (2005) 419.
13 E. Horváth, J. Kristóf, R. L. Frost, Á. Rédey, V. Vágvölgyi and T. Cseh, J. Therm. Anal. Cal., 71 (2003) 707.

14 F. Franco and M. D. Ruiz Cruz, J. Therm. Anal. Cal., 73 (2003) 151.

15 I. A. Pastre, Oliveira I. do Nascimento, A. B. S. Moitinho, G. R. de Souza, E. Y. Ionashiro and F. L. Fertonani, J. Therm. Anal. Cal., 75 (2004) 661.

16 W. B. Xu, Z. F. Zhou, P. S. He and W-P. Pan, J. Therm. Anal. Cal. 78 (2004) 113.

17 L. J. Stein, Am. Chem. Soc., 81 (1959) 1273.

18 N. F. Yudanov and I. I. Yakovlev, Izv. Sib. Branch of USSR Acad. of Sciences, Ser. Chem. Sciences, Part 1, (1988), 166 (in Russian).

19 V. A. Logvinenko, Thermal Analysis of Coordination Compounds and Clathrates, Novosibirsk, Nauka, Siberian Department, 1982 (in Russian).

20 K. I. Patrilyak, Inclusion compounds and certain problems of heterogeneous equilibria, Kiev, Naukova Dumka 1987, (in Russian).

21 E. A. Ukraintseva and G. N. Chekhova, IX ${ }^{\text {th }}$ International Seminar on Inclusion Compounds, Novosibirsk, Russia, June 22-27 (2003) 108 (in Russian).

Received: July 29, 2005

Accepted: August 4, 2005

OnlineFirst: December 12, 2005

DOI: $10.1007 / \mathrm{s} 10973-005-7130-9$ 